OPEN ACCESS

Edited by:

Edward A. Selby,

Rutgers, The State University of New

Jersey, United States

Reviewed by:

Clement Zai,

Center for Addiction and Mental Health (CAMH), Canada Joanne Kim,

Rutgers, The State University of New Jersey, United States

*Correspondence:

Jeong-Ho Chae alberto@catholic.ac.k

Specialty section:

This article was submitted to

Psychopathology,

a section of the journal

Frontiers in Psychiatry

Received: 08 June 2020 Accepted: 25 February 2021 Published: 29 March 2021

Citation:

Tae H and Chae J-H (2021) Factors Related to Suicide Attempts: The

Roles of Childhood Abuse and Spirituality.

Front. Psychiatry 12:565358. doi: 10.3389/fpsyt.2021.565358

\section{Factors Related to Suicide Attempts: The Roles of Childhood Abuse and Spirituality}

\author{
Hyejin Tae ${ }^{1}$ and Jeong-Ho Chae ${ }^{2 *}$ \\ ${ }^{1}$ Stress Clinic, Health Promotion Center, Seoul St. Mary's Hospital, The Catholic University of Korea, Seoul, South Korea, \\ ${ }^{2}$ Department of Psychiatry, Seoul St. Mary's Hospital, The Catholic University of Korea, Seoul, South Korea
}

Objectives: The purpose of this article was to identify independent factors associated with suicide attempts in patients with depression and/or anxiety.

Background and Aims: This study was conducted in order to examine whether risk and protective psychological factors influence the risk of suicide attempts among outpatients with anxiety and/or depressive disorders. In this regard, explanatory models have been reported to detect high-risk groups for suicide attempt. We also examined whether identified factors serve as mediators on suicide attempts.

Materials and Methods: Patients from 18 to 65 years old from an outpatient clinic at Seoul St. Mary's Hospital were invited to join clinical studies. From September 2010 to November 2017, a total of 737 participants were included in the final sample. The Beck Depression Inventory (BDI), State-Trait Anxiety Inventory (STAI), Childhood Trauma Questionnaire (CTQ), Functional Assessment of Chronic Illness Therapy-Spiritual Well-being Scale (FACIT-Sp-12), and Functional Social Support Questionnaire (FSSQ) were used to assess psychiatric symptoms. An independent samples t-test, a chi-square test, hierarchical multiple regression analyses, and the Baron and Kenny's procedures were performed in order to analyze data.

Results: Young age, childhood history of emotional and sexual abuse, depression, and a low level of spirituality were significant independent factors for increased suicide attempts. Depression was reported to mediate the relationship between childhood emotional and sexual abuse, spirituality, and suicide attempts.

Conclusions: Identifying the factors that significantly affect suicidality may be important for establishing effective plans of suicide prevention. Strategic assessments and interventions aimed at decreasing depression and supporting spirituality may be valuable for suicide prevention.

Keywords: suicide attempts, depression, childhood sexual abuse, childhood emotional abuse, spirituality

\section{INTRODUCTION}

Approximately $90 \%$ of people who commit suicide are considered to have at least one psychiatric disorder at the time of death $(1,2)$. Of these psychiatric disorders, mood and anxiety disorders have been particularly identified as critical determinants of suicide (3-6). In addition, sociodemographic factors, such as being male, unmarried, and unemployed (7), as well as exposure to childhood 
trauma (8) are recognized as independent risk factors for suicide. Earlier studies have showed that childhood abuse is an important risk factor for violent behaviors toward the self and a key factor to consider for the effective prevention of suicide (9-11). Several studies have also suggested that childhood abuse is related to internalizing (depression and anxiety) and externalizing (substance abuse and antisocial behavior) dimensions underlying psychiatric disorders, and that both of these dimensions are related to suicide attempts $(12,13)$.

Although there is a substantial amount of literature on suicide risk factors $(14,15)$, much less is known about the protective factors for suicide (16). In recent decades, some researchers have started to recognize the importance of identifying these protective factors $(17,18)$. Several studies have reported that spirituality is associated with lower suicide risk and better mental health $(19,20)$. Spirituality has been defined as "the personal search for understanding life's meaning and the goal of life" (21). Koenig et al. (21) reported that spiritual belief and practices such as meditation, prayer, and communal worship tend to arouse positive and supportive emotions from participants. Other studies have also indicated that the protective effect of spiritual values might be affected by the influence of social support (22). The presence of social support may increase feelings of belongingness, which are negatively associated with suicide risk within Joiner's Interpersonal Theory of Suicide $(23,24)$. Given the importance of mental illness in the context of suicide (25), it is important to understand the relationship between spirituality, social support, and suicide attempts in populations of people with depression.

Regardless of the agreement among the empirical studies on whether the presence of spiritual beliefs and social support is related to increased resiliency to suicide, the majority of previous studies have not considered both spirituality and social support for suicide. Therefore, studies which examine both factors affecting suicide would be meaningful for suicide protection. In particular, spirituality has some characteristics such as social practices similar to social support. To differentiate both positive factors, we considered spirituality as spiritual beliefs, an affective aspect of spirituality and a cognitive aspect of spirituality. The spiritual practices including communal worship were excluded to differentiate the other positive factor such as social support. Therefore, we identified both relationships between spirituality and suicide attempts, and between social support and suicide attempts, respectively.

The purpose of this study was to examine whether risk and protective factors influence the risk of suicide attempts among outpatients with anxiety and/or depressive disorders. First, we classified patients with anxiety and/or depressive disorder into two groups by the presence or absence of a history of suicide attempts. Then, both groups were compared in terms of sociodemographic factors, psychiatric symptoms, histories of childhood trauma, and positive psychological factors such as spirituality and social support. We used suicide attempts as an outcome variable because suicide attempts are a definite indicator of suicidality (26). We then evaluated the effects of the positive and negative factors which were considered to be related to suicide attempts. Finally, we examined whether the identified significant factors served as mediators on the risk of suicide attempts. According to the prior research findings described above, we formulated three hypotheses: that childhood abuse among different types of childhood maltreatment would be related to the increased suicide attempts, that positive factors such as spirituality and social support would be related to the decreased suicidal behavior, and that depression would mediate the relationship between significant positive/negative factors and suicide attempts.

\section{METHODS}

\section{Participants and Procedures}

Treatment-seeking patients from 18 to 65 years old from the Mood and Anxiety Disorders Clinic at Seoul St. Mary's Hospital, The Catholic University of Korea were invited to join clinical studies. From September 2010 to November 2017, the participants underwent an assessment that comprised several health and behavioral aspects as well as a psychological evaluation at their first visit before treatment. Patients who met the DSM-IV criteria for depressive and/or anxiety disorders were included in this study. Relevant diagnoses were made by a psychiatrist using structured interviews of the Mini-International Neuropsychiatric Interview (M.I.N.I) (27). A lifetime diagnosis of psychotic disorder, bipolar disorder, intellectual disability, current substance abuse, any mental disorder due to another medical condition as well as medical problems affecting study participation were exclusion criteria. A total of 751 outpatients who met the inclusion criteria participated in the study and were administered a battery of self-report psychiatric questionnaires. Excepting analyses of those who had not completed all measures, the final sample included 737 patients. This investigation was carried out in accordance with the latest version of the Declaration of Helsinki. This study was approved by the Institutional Review Board of the Ethics Committee of Seoul St. Mary's Hospital at The Catholic University of Korea (KC09FZZZ0211). Written informed consent was obtained from all subjects after providing them with a complete description of the study.

\section{Measurements}

\section{Sociodemographic, Clinical Information, and Suicide Attempts}

Sociodemographic and clinical information were acquired from medical charts and interviews with patients and their caretakers. Data on age, gender, education, marriage status and employment status were obtained in the study. Education was estimated by the years of formal education. Marital status was categorized as married and unmarried (including single, divorced, and widowed). Employment status was categorized as employed (including permanent and precarious employment) and unemployed. In this study, the definition of unemployed included all subjects who were without work regardless of whether they were looking for work or not. Suicidality was assessed according to the following question: "Have you ever attempted suicide in the past?" There is supporting evidence that past suicide attempt is a leading risk factor for future attempts 
and death by suicide $(28,29)$. Positive responses were confirmed by follow-up questions that assessed the number, method, and subjective seriousness of these attempts.

\section{Psychiatric Symptoms}

The Beck Depression Inventory (BDI) was used to assess depressive symptoms. The BDI consists of 21 items on a 4-point scale from 0 (symptom absent) to 3 (severe symptoms) and is a self-report inventory for evaluating the severity of depression. The BDI evaluates depressive symptoms within the preceding week, with high scores reflecting a greater severity of depressed mood (range $=0-63$ ) (30). The Korean version of BDI used here has been validated (31-33).

Anxiety was evaluated by the State-Trait Anxiety Inventory (STAI). The STAI consists of two scales, each containing 20 items using a 4-point Likert scale. First, the State Anxiety Scale (S-Anxiety) assesses the current state of anxiety, asking how respondents feel "right now," including subjective feelings of apprehension, tension, nervousness, worry, and activation/arousal of the autonomic nervous system. The Trait Anxiety Scale (T-Anxiety) assesses relatively stable aspects of "anxiety proneness" using items that measure general states of calmness, confidence, and security. When the scores on each item are added up, a total summed score is obtained. We used a total summed score to assess anxiety. The range of scores for each subtest is $20-80$, with a higher score implying greater anxiety (34). Validation of the Korean version of STAI has proven its reliability and sensitivity in the measurement of anxiety (35).

\section{Childhood Trauma}

Childhood trauma was measured using the short form of the Childhood Trauma Questionnaire (CTQ). The CTQ yields scores for childhood physical neglect, emotional neglect, physical abuse, emotional abuse, and sexual abuse, as well as a total score. The short version of CTQ is a 5-item Likert scale on which the respondents rate the frequency of 28 sentences about childhood trauma experiences (36-38). The CTQ measures the severity of symptoms as none, low, moderate, or severe, and we used a moderate-to-severe cutoff point (39). Validation of the Korean version of CTQ has proven its reliability and sensitivity (40).

\section{Positive Psychological Factors}

Spiritual well-being was assessed using the Functional Assessment of Chronic Illness Therapy-Spiritual Well-being Scale (FACIT-Sp-12) (41). This scale is divided into three factors: faith (spiritual beliefs), peace (an affective aspect of spirituality), and meaning (a cognitive aspect of spirituality) $(42,43)$. The FACIT-Sp-12 has a 5 -point Likert-style response scale $(0=$ not at all, $1=$ a little bit, $2=$ somewhat, $3=$ quite a bit, $4=$ very much), and when the scores on all the items are added up, a total summed score is obtained (two items are reverse-scored). The Korean version has not been officially validated, but it has been used in a domestic study. In that study, Cronbach alpha was 0.751 , and spiritual well-being correlated negatively with anxiety $(\mathrm{r}=-0.613)$ and depression $(\mathrm{r}=-0.526$, all $p<0.05)$, attesting to the concurrent validity of the FACIT-sp (44). The internal consistency of our study as measured by the Cronbach's alpha coefficient was been found to be 0.76 for the Spiritual Well-being subscale.

Social support was measured by the Functional Social Support Questionnaire (FSSQ), an eight-item questionnaire which assesses the strength of one's social network. It consists of two domains: confidential social support and affective social support. The score of the scale ranges from 11 to 55 , where 55 indicates the highest levels of social support. Validation of the Korean version of FSSQ has proven its reliability and sensitivity in the measurement of social support (45).

\section{Data Analysis}

Participants were classified into either the suicide attempt group or the no suicide attempt group based on the responses of a self-report form assessing suicidality. The characteristics of the participants were reported as means (standard deviation [SD]) for continuous variables, and as numbers (\%) for categorical variables. Two-tailed tests were used in all instances, and statistical significance was defined as $p<0.05$ with confidence intervals at $95 \%$. In order to identify the relationship between each of these variables and suicide attempts, an independent samples $t$-test was performed for each continuous variable and a chi-square test was performed for each categorical variable.

Hierarchical multiple regression analyses were performed in order to evaluate whether each positive and negative factor is related to suicide attempts or not. The principle of "factors coming earlier in the series can affect other factors coming later, but not vice versa" was used to decide the order of the included variables (46). In the four-block model, we initially included demographic data to adjust for the effects of demographic differences. Then, childhood trauma, positive psychological factors, and clinical symptoms were entered into blocks 2, 3, and 4, respectively, according to the guidelines. Because childhood trauma is known as one of the distal factors which affect suicide risk (4), we entered this variable into block 2. Next, positive factors such as spirituality and social support have long been regarded as mitigating distress $(47,48)$. Social support has been found to be inversely related to depression and anxiety (49). Moreover, spirituality plays a key role in helping depressive patients cope with stress $(50,51)$. Because protective factors have been known to decrease psychiatric symptoms such as depression and anxiety, positive factors and clinical symptoms were included in blocks 3 and 4 . A forward selection method was used in the multiple regression analyses because intercorrelations between variables were expected.

In the final part of the study, we performed mediating analysis in order to understand the relationship between significant factors and suicidal ideation. Baron and Kenny's procedures were used to examine the mediating effect of depression (52). Past studies have shown that the association between childhood abuse and suicidal behaviors was mediated by mental disorders such as depression (53-55). In addition, other studies have described that spirituality and social support provide protective effects regarding suicide attempts (56) and are associated with decreased rates of depression (57). According to these previous studies, we confirmed a relationship between each independent variable (i.e., childhood trauma and positive factors) 
TABLE 1 | Demographic and psychiatric characteristics, childhood trauma, and positive factors of subjects with anxiety and/or depression by suicide attempt history.

\begin{tabular}{|c|c|c|c|}
\hline Variable & $\begin{array}{l}\text { No suicide attempt history } \\
\qquad(n=554,75.2 \%)\end{array}$ & $\begin{array}{l}\text { Suicide attempt history } \\
\qquad(n=183,24.8 \%)\end{array}$ & $p^{a}$ \\
\hline \multicolumn{4}{|l|}{ DEMOGRAPHIC CHARACTERISTICS } \\
\hline Age, years, mean \pm SD & $38.3 \pm 13.4$ & $30.7 \pm 11.1$ & $<0.001^{\star \star}$ \\
\hline Gender (female), no. (\%) & $305(55.5)$ & $97(53.3)$ & 0.668 \\
\hline Education, years, mean \pm SD & $14.3 \pm 2.8$ & $13.6 \pm 2.4$ & $0.002^{* \star}$ \\
\hline Marriage status (Unmarried), no. (\%) & $278(50.2)$ & $119(76.5)$ & $<0.001^{\star *}$ \\
\hline Employment status (no), no. (\%) & $244(44.0)$ & $108(59.0)$ & $0.001^{\star \star}$ \\
\hline \multicolumn{4}{|l|}{ PSYCHIATRIC CHARACTERISTICS } \\
\hline Depression (BDI), mean \pm SD & $21.8 \pm 10.9$ & $31.0 \pm 10.7$ & $<0.001^{\star \star}$ \\
\hline Anxiety (STAl), mean \pm SD & $115.4 \pm 23.9$ & $130.4 \pm 19.6$ & $<0.001^{\star *}$ \\
\hline \multicolumn{4}{|l|}{ CHILDHOOD TRAUMA (CTQ) } \\
\hline Emotional abuse (yes), no. (\%) & $8.2(4.5)$ & $11.6(5.8)$ & $<0.001^{\star \star}$ \\
\hline Physical abuse (yes), no. (\%) & $8.6(4.5)$ & $10.8(5.5)$ & $<0.001^{\star \star}$ \\
\hline Sexual abuse (yes), no. (\%) & $6.1(2.6)$ & $7.5(4.3)$ & $<0.001^{\text {** }}$ \\
\hline Emotional neglect (yes), no. (\%) & $12.5(5.4)$ & $15.1(5.9)$ & $<0.001^{\star \star}$ \\
\hline Physical neglect (yes), no. (\%) & $8.0(3.3)$ & $8.7(3.6)$ & $0.035^{\star}$ \\
\hline \multicolumn{4}{|l|}{ POSITIVE FACTORS } \\
\hline Spirituality (FACIT-Sp-12), mean \pm SD & $22.1 \pm 10.0$ & $13.7 \pm 9.4$ & $<0.001^{\star \star}$ \\
\hline Social support (FSSQ), mean \pm SD & $40.3 \pm 11.6$ & $35.2 \pm 12.0$ & $<0.001^{\star \star}$ \\
\hline
\end{tabular}

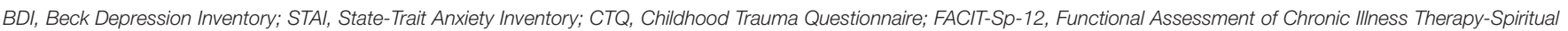
Well-being Scale; FSSQ, Functional Social Support Questionnaire; SD, standard deviation.

a Statistical significance from independent $t$-tests or chi-square tests.

${ }^{\star} p<0.05,{ }^{* *} p<0.01$.

and the dependent variable (i.e., suicide attempts) in the logistic regression analysis in Step 1. In Step 2, simple linear regression analysis was conducted in order to confirm a relationship between the independent variables and the mediator variable (i.e., depression). In Step 3, logistic regression analysis was used to confirm relationships between the mediator and the dependent variable after controlling for the predictor variables. Then, we confirmed the relationships between the independent variables and the dependent variable after controlling for the mediator in Step 4. The Sobel test (58) was then employed in order to determine the indirect effects of the mediator variable on the association between predictor variables and the outcome variable. All analyses were conducted with SPSS version 21.0 for Windows (SPSS, Inc., and IBM Company, Chicago, IL, USA).

\section{RESULTS}

\section{Demographic Characteristics, Related Risk, and Positive Factors With Suicide Attempts}

Sociodemographic and psychiatric characteristics, childhood trauma history, and positive psychological factors of subjects in the two groups (having a history of suicide attempts and having no history of suicide attempts) are shown in Table 1. Approximately two-thirds (75.2\%) of participants were classified with no suicide attempt history while approximately one-third $(24.8 \%)$ of participants were classified with suicide attempt history. Five hundred and fifty-four participants without suicide attempt history had a mean age of $38.3( \pm 13.4)$ years with 305 females (55.5\%) and 245 males (44.5\%). The mean years of education was $14.3( \pm 2.8)$ years. Half of them were unmarried (50.2\%) and majority of them were employed (56.0\%). On the other hand, 183 participants with a history of suicide attempts had a mean age of $30.7( \pm 11.1)$ years with 97 females (53.3\%) and 85 males (46.7\%). The mean years of education was $13.6( \pm 2.4)$ years. Majority of them were unmarried (76.5\%) and unemployed (59\%). Comparing sociodemographic factors between the two groups according to suicide attempt history, subjects with a history of suicide attempts tended to be younger $(p<0.001)$, less educated ( $p$ $=0.002)$, be less employed $(p=0.001)$, and live alone $(p<$ $0.001)$. There were no significant gender differences between the two groups.

The mean BDI and STAI scores of participants with a history of suicide attempts were $31.0( \pm 10.7)$ and $130.4( \pm 19.6)$ which belong to the ranges of severe depression and anxiety $(45,59-$ 61). These scores were significantly higher than the scores of participants with no history of suicide attempts $(p<0.001)$. People with a history of suicide attempts had significantly higher scores in all areas of childhood trauma questionnaires than those without a history of suicide attempts $(p<0.001)$. Considering positive factors, subjects with suicide attempt history tended to have lower FACIT-Sp-12 $(p<0.001)$ and FSSQ $(p<0.001)$ scores than those without suicide attempt history. In other words, participants with a history of suicide attempts had lower spirituality and social support than those with no history of suicide attempts. 
TABLE 2 | Results of hierarchical logistic regression model to identify factors related to suicide attempts.

\begin{tabular}{|c|c|c|c|c|c|c|c|c|}
\hline \multirow[t]{2}{*}{ Block no., variable } & \multicolumn{6}{|c|}{$\begin{array}{l}\text { Results of each step using forward } \\
\text { stepwise method in blocks } 2-4\end{array}$} & \multicolumn{2}{|c|}{ Last step results } \\
\hline & OR (95\%Cl) & $p$ & OR (95\%Cl) & $p$ & OR (95\%Cl) & $p$ & OR (95\%Cl) & $p$ \\
\hline \multicolumn{9}{|l|}{ CONSTANT } \\
\hline \multicolumn{9}{|l|}{ 1. Covariates } \\
\hline Age, years & $0.97(0.95-0.99)$ & $0.001^{\star *}$ & 0.97 (0.95-0.99) & $0.001^{\star \star}$ & $0.98(0.96-0.10)$ & $0.027^{\star}$ & $0.97(0.95-1.00)$ & $0.017^{*}$ \\
\hline Gender (female) & $0.76(0.52-1.12)$ & 0.164 & $0.90(0.60-1.35)$ & 0.625 & $0.89(0.58-1.35)$ & 0.571 & $0.98(0.64-1.50)$ & 0.914 \\
\hline Marriage status (Unmarried) & $0.44(0.26-0.74)$ & $0.002^{\star \star}$ & 0.53(0.31-0.91) & $0.022^{*}$ & $0.68(0.39-1.19)$ & 0.176 & $0.65(0.37-1.14)$ & 0.135 \\
\hline Education, years & $0.96(0.89-1.03)$ & 0.208 & 0.97 (0.90-1.05) & 0.476 & $0.98(0.90-1.06)$ & 0.556 & $0.98(0.91-1.07)$ & 0.680 \\
\hline Employment status (no) & $0.68(0.47-0.99)$ & $0.043^{\star}$ & $0.71(0.48-1.05)$ & 0.085 & $0.76(0.50-1.14)$ & 0.182 & $0.78(0.51-1.18)$ & 0.239 \\
\hline \multicolumn{9}{|l|}{ 2. Childhood trauma } \\
\hline $\begin{array}{l}\text { Emotional abuse } \\
\text { (yes) }\end{array}$ & & & 1.07 (1.02-1.12) & $0.011^{*}$ & $1.07(1.02-1.13)$ & $0.010^{*}$ & $1.06(1.01-1.12)$ & $0.028^{*}$ \\
\hline $\begin{array}{l}\text { Physical abuse } \\
\text { (yes) }\end{array}$ & & & 1.02 (0.97-1.07) & 0.465 & $1.02(0.97-1.07)$ & 0.497 & $1.01(0.96-1.06)$ & 0.611 \\
\hline Sexual abuse (yes) & & & 1.09 (1.03-1.16) & $0.005^{\star \star}$ & $1.09(1.03-1.17)$ & $0.007^{\star *}$ & $1.09(1.02-1.17)$ & $0.012^{*}$ \\
\hline $\begin{array}{l}\text { Emotional neglect } \\
\text { (yes) }\end{array}$ & & & $1.03(0.98-1.07)$ & 0.242 & $1.00(0.96-1.05)$ & 0.966 & $1.01(0.96-1.06)$ & 0.665 \\
\hline $\begin{array}{l}\text { Physical neglect } \\
\text { (yes) }\end{array}$ & & & $0.98(0.92-1.05)$ & 0.616 & $0.99(0.92-1.06)$ & 0.737 & $0.98(0.91-1.06)$ & 0.628 \\
\hline \multicolumn{9}{|l|}{ 3. Positive factors } \\
\hline $\begin{array}{l}\text { Spirituality } \\
\text { (FACIT-Sp-12) }\end{array}$ & & & & & $0.93(0.90-0.96)$ & $<0.001^{* \star}$ & $0.94(0.91-0.98)$ & $0.001^{* *}$ \\
\hline $\begin{array}{l}\text { Social support } \\
\text { (FSSQ) }\end{array}$ & & & & & $1.01(0.99-1.03)$ & 0.562 & $1.01(0.99-1.03)$ & 0.344 \\
\hline \multicolumn{9}{|l|}{ 4. Psychiatric characteristics } \\
\hline Depression (BDI) & & & & & & & $1.05(1.02-1.08)$ & $0.001^{\star *}$ \\
\hline Anxiety (STAl) & & & & & & & $0.10(0.98-1.01)$ & 0.693 \\
\hline \multicolumn{9}{|l|}{ MODEL FIT } \\
\hline Hosmer and Lemeshow test & $x^{2}=5.694, p$ & 0.681 & $x^{2}=1.842, p$ & 0.985 & $\chi^{2}=2.223, p$ & 0.973 & $\chi^{2}=8.080, p$ & .426 \\
\hline
\end{tabular}

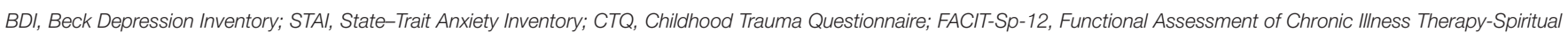
Well-being Scale; FSSQ, Functional Social Support Questionnaire. Hierarchical multivariate logistic regression analysis was performed. ${ }^{*} p<0.05,{ }^{* *} p<0.01$.

\section{Independent Effect of Negative and Positive Factors on Suicide Attempts}

Table 2 shows the results of a hierarchical multivariate logistic regression analysis examining the factors related to suicide attempts. After controlling for demographic covariates, a high grade of childhood trauma, low spirituality, low social support, and high levels of depression and anxiety symptoms were included in the model step by step. In the final model, being of a young age [adjusted [adj.] OR $=0.97$ (0.951.00)] and having experienced a high level of emotional abuse [adj. OR $=1.06(1.01-1.12)$ ] and a high level of sexual abuse [adj. OR $=1.09(1.02-1.17)$ ], as well as low spirituality [adj. OR $=0.94(0.91-0.98)$ ] were all independently associated with suicide attempts. In particular, a high grade of childhood sexual abuse was the most influential variable on suicide attempts. The overall model fits the data well (Hosmer and Lemeshow test of goodness-of-fit $\chi^{2}=8.08$, $p=0.426)$.

\section{Mediating Effects of Depression on Patients' Suicide Attempts}

All four steps of Baron and Kenny's analysis were performed in order to examine the mediating roles of depressive symptoms in the relationships between childhood emotional abuse, childhood sexual abuse, spirituality, and suicide attempts. As shown in Table 3, the results of mediation analyses showed that the total effect of childhood emotional abuse on suicide attempts was significant $(\beta=0.121, \mathrm{SE}=0.016, p<0.001)$. The significant coefficient of path a $(\beta=0.238, \mathrm{SE}=0.988, p<0.001)$ and path $\mathrm{b}(\beta=0.064, \mathrm{SE}=0.009, p<0.001)$ indicated positive associations of childhood emotional abuse on depression, and depression on suicide attempts. Besides, the indirect effect of childhood emotional abuse on suicide attempts through depression was statistically significant $(\beta=0.092$, $\mathrm{SE}=0.017$, $p<0.001)$. Therefore, depression significantly mediated the effect of childhood emotional abuse on suicide attempts (see Figure 1). 
TABLE 3 | Mediating effects of depression on patients' suicide attempts.

\begin{tabular}{|c|c|c|c|c|c|}
\hline & $\beta$ & $S E$ & $p$ & $\operatorname{Exp}(B)$ & Adjusted $R^{2}$ \\
\hline \multicolumn{6}{|l|}{ Model 1} \\
\hline Emotional abuse $\rightarrow$ Suicidal attempt & 0.121 & 0.016 & $<0.001$ & 1.129 & 0.110 \\
\hline Emotional abuse $\rightarrow$ Depression & 0.238 & 0.988 & $<0.001$ & & 0.055 \\
\hline Depression $\rightarrow$ Suicidal attempt & 0.064 & 0.009 & $<0.001$ & 1.066 & 0.216 \\
\hline Emotional abuse $\rightarrow$ Suicidal attempt excluding Depression & 0.092 & 0.017 & $<0.001$ & 1.097 & \\
\hline \multicolumn{6}{|l|}{ Sobel test $z=-4.36, p=<0.001$} \\
\hline \multicolumn{6}{|l|}{ Model 2} \\
\hline Sexual abuse $\rightarrow$ Suicidal attempt & 0.116 & 0.025 & $<0.001$ & 1.123 & 0.044 \\
\hline Sexual abuse $\rightarrow$ Depression & 0.138 & 1.092 & $<0.001$ & & 0.018 \\
\hline Depression $\rightarrow$ Suicidal attempt & 0.069 & 0.008 & $<0.001$ & 1.072 & 0.186 \\
\hline Sexual abuse $\rightarrow$ Suicidal attempt excluding Depression & 0.087 & 0.027 & 0.001 & 1.091 & \\
\hline \multicolumn{6}{|l|}{ Sobel test $z=-2.35, p=0.001$} \\
\hline \multicolumn{6}{|l|}{ Model 3} \\
\hline Spirituality $\rightarrow$ Suicidal attempt & -0.094 & 0.011 & $<0.001$ & 0.910 & 0.187 \\
\hline Spirituality $\rightarrow$ Depression & -0.492 & 0.740 & $<0.001$ & & 0.241 \\
\hline Depression $\rightarrow$ Suicidal attempt & 0.044 & 0.010 & $<0.001$ & 1.045 & 0.220 \\
\hline Spirituality $\rightarrow$ Suicidal attempt excluding Depression & -0.065 & 0.012 & $<0.001$ & 0.938 & \\
\hline Sobel test $z=-3.31, p=<0.001$ & & & & & \\
\hline
\end{tabular}

Baron and Kenny's procedures were used to examine the mediating effects of depression.

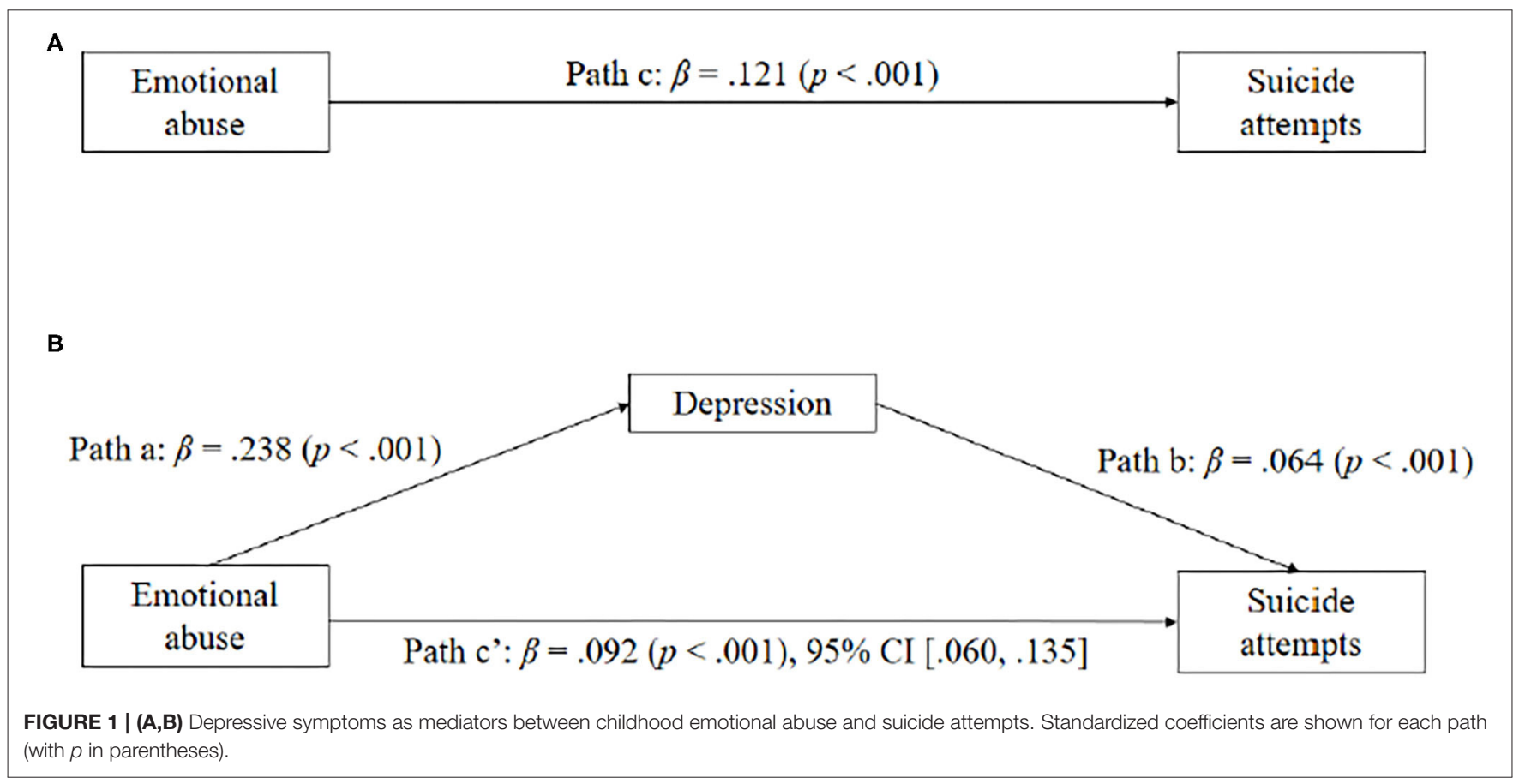

Significant effects were also observed for childhood sexual abuse on depression $(\beta=0.138, \mathrm{SE}=1.092, p<0.001)$, depression on suicide attempts $(\beta=0.069, \mathrm{SE}=0.008, p$ $<0.001$ ), and childhood sexual abuse on suicide attempts $(\beta=0.116, \mathrm{SE}=0.025, p<0.001)$. Notably, the indirect effect of childhood sexual abuse on suicide attempts through depression was significant $(\beta=0.087, \mathrm{SE}=0.027, p=$ $0.001)$. The pattern of the mediating effects of depression between childhood sexual abuse and suicide attempts is depicted in Figure 2.

Figure 3 displays the model of spirituality as a predictor of suicide attempts, mediated by depression. When depression was excluded in the model, spirituality significantly predicted suicide attempts $(\beta=-0.094, \mathrm{SE}=0.011, p<0.001)$. The simple mediation analysis with suicide attempts as the outcome indicated that spirituality significantly predicted depression $(\beta$ 

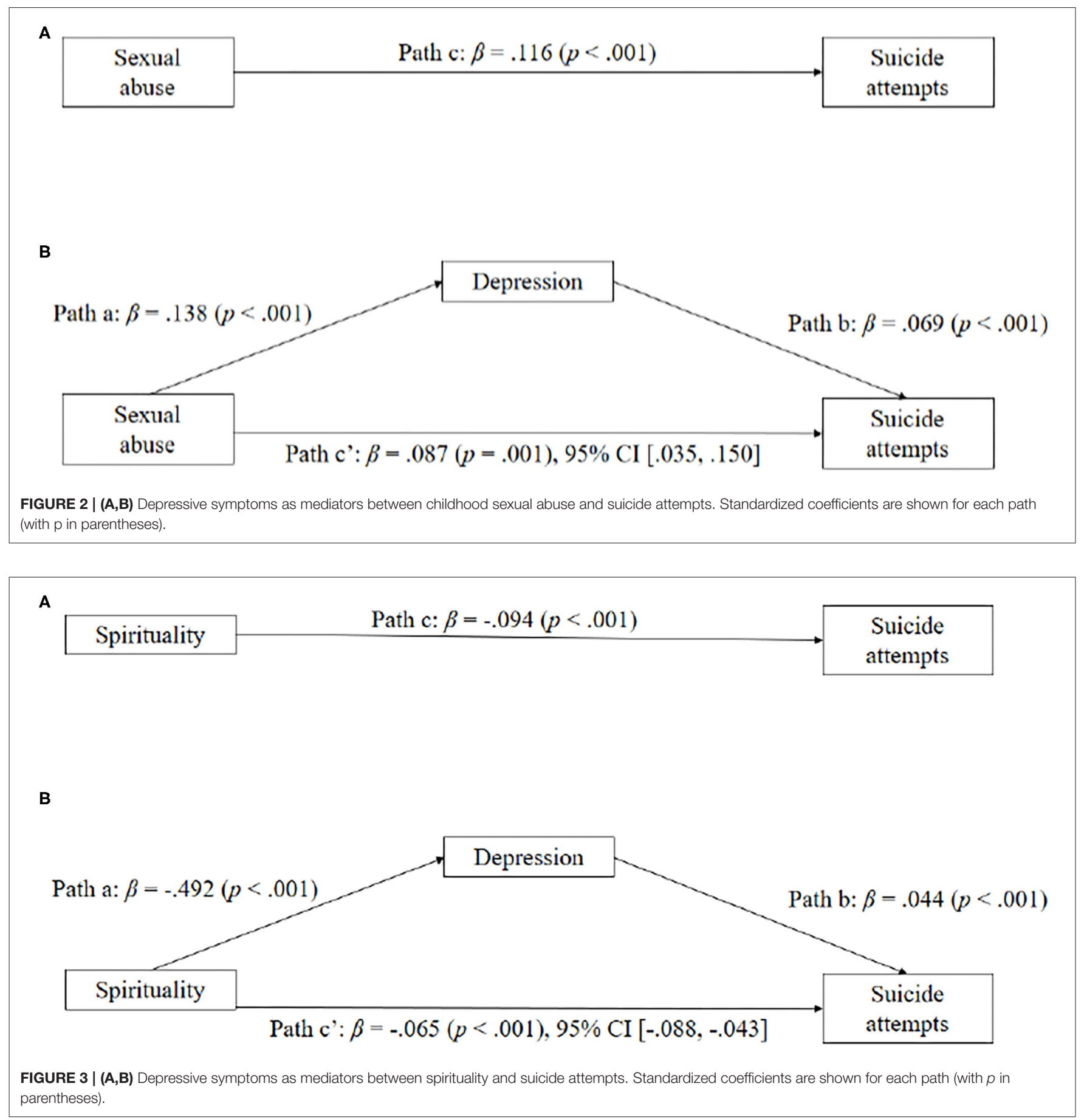

$=-0.492, \mathrm{SE}=0.740, p<0.001)$. The association was negative: as spirituality increased, depression severity declined (and vice versa). Spirituality significantly predicted suicide attempts even with relationship depression in the model ( $\beta$ $=-0.065, \mathrm{SE}=0.012, p<0.001)$ and depression also significantly predicted suicide attempts $(\beta=0.044, \mathrm{SE}=0.010$, $p<0.001)$. As depression severity increased, suicide attempts increased as well (and vice versa), and as spirituality increased, suicide attempts decreased. Consistent with our hypothesis, depression significantly mediated the effect of spirituality on suicide attempts.

\section{DISCUSSION}

In the present study on patients with depression and/or anxiety disorders, being young, having experienced a high level of childhood emotional and sexual abuse, and having a 
high level of depression and low level of spirituality were all significant independent factors for increased suicide attempts after controlling for sociodemographic factors, childhood trauma history, positive psychological factors, and psychiatric symptoms. In particular, depressive symptoms were identified as partially mediating the relationships between childhood emotional and sexual abuse, spirituality, and suicide attempts.

The findings of our study were consistent with those of previous studies that depression was significantly related to suicidality (62-64). It is therefore important to identify the close relationship between suicide and depression distinct from anxiety. The first possible connecting link between these two factors is hopelessness. Wolfe et al. (65) reported that hopelessness is a mediator of suicidal ideation in depressive adolescent youth. A strong relationship among depression, suicide, and hopelessness as a mediator was demonstrated in a non-clinical sample in another study (66). The second factor affecting suicidality was identified as anhedonia. Research has suggested that anhedonia may be a unique symptom of depression associated with thoughts of suicide (63). Those who have suicidality are less interested in experiencing pleasure and try to avoid intolerable psychological pain, which motivates them to think about suicide (64). In other words, hopelessness and anhedonia, which are intimately related with depression other than anxiety, are important factors associated with suicide.

Several studies have reported that sexual abuse history in particular has a noticeable effect on the risk of suicide (67-69). Brown et al. proposed that, among various types of childhood trauma, sexual abuse alone was the strongest independent risk factor for suicide (70). Ryan demonstrated that those who had a history of childhood sexual trauma may respond to anger, even if there is no danger related to the traumatic experience (71). The effects of traumatic events and depression on anger, particularly internal hostility, are related to suicide risk, suggesting a potential mechanism of childhood sexual trauma and suicide linkage (72). On the other hand, childhood emotional abuse is an independent risk factor of suicide with its effects on interpersonal relationships (73). Emotional difficulties arousing from negative relationships between the exploiter caregiver and the abused child may be internalized and responsible for long-term effects on negative cognitions (74). Those with a history of emotional abuse may have schemas of deficiency, shame, and self-sacrifice, which may induce emotional problems and depression (75). Therefore, it was concluded that sexual and emotional abuse was a significant determinant of predisposition to suicide.

As our study has shown, spirituality was a significant factor having a meaningful protective effect on suicide. It has been reported that spirituality may increase senses of intimacy as well as enhance a feeling of comfort and relief (76), provide hope in one's life $(77,78)$, and decrease physical, psychological, and social difficulties $(76,79,80)$. High spirituality helps individuals apply a positive coping style against stress (81) and decrease suicide in various populations (82-84). Wu et al. (85) has shown that religion is a positive factor against completed suicide in a majority of settings where suicide research is conducted using a meta-analysis. Thus, taking a spiritual history is not only necessary to identify spiritual resources that can be used to facilitate psychological well-being, but also to identify ability that may directly impact on suicide prevention.

A spiritual history can be included as part of the social history at the time of hospital admission, during a new patient evaluation, or as part of an outpatient visit (86). There is also evidence that addressing spiritual issues enhances the doctorpatient relationship and helps to build trust (87). If spiritual needs are identified, then spirituality-based intervention can be introduced. Especially, mindfulness is a practice that has long been associated with spiritual development $(88,89)$. Because mindfulness has its roots in Asian culture, it especially can be an effective intervention to enhance spirituality among Koreans. Yong et al. demonstrated that spirituality training program including mindfulness meditation showed beneficial effects on spiritual well-being for middle manager nurses in Korea (90). The significant improvement in spiritual well-being and spiritual integrity in the experimental group was supported by similar results in other health care professionals $(91,92)$. Therefore, spirituality-based programs can be introduced within continuing education and staff development programs for mental health professionals.

Although there is some evidence that social support is associated with decreasing suicide risk in patients with depression $(93,94)$, we did not identify this independent relationship among the two. Social support is defined as the perception of the individual regarding relationships with other positive resources that assist the individuals to cope not only with every day events, but also with stressful situations $(95,96)$. Because FSSQ aims to measure the person's satisfaction with functional and affective aspects of the individual's social support (97, 98), not all aspects and sources of social support may be evaluated. Some studies have also suggested that depressive symptoms are mediating factors which affect the relationship between suicide and psychosocial factors $(99,100)$. Depression might weaken the protective effect of social support on suicide attempts. Therefore, the mediating effects of depressive symptoms on the association between social support and suicide should be considered in interpreting the results.

Our study does have some limitations. First, we used selfreporting scales to assess psychological symptoms, including BDI, STAI, CTQ, FACIT-Sp-12, and FSSQ; self-reporting can exaggerate the reported severity of symptoms $(101,102)$. Second, because of the cross-sectional design of this study, we cannot certainly infer causality between suicide attempts and the other variables studied. Therefore, further study with a prospective design which identifies causality may be needed in order to clarify how significant factors such as spirituality contribute to the alleviation of the effects of the risk factors on suicide. Third, despite the classification between anxiety and/or depressive disorder, we considered the two disorders as one group. One of the most prevalent findings in psychiatry is the frequent comorbidity between anxiety disorders and depressive disorders (103). Co-morbidity has many origins such as genetic factors $(104,105)$ and environmental experiences, including stressful life events $(106,107)$. Although anxiety disorders and depressive disorders have displayed frequent comorbidity, the specificity of each diagnosis may be identified in order to differentiate 
between the outcomes in the different populations (108). Fourth, despite the various severities of depressive symptoms, we regarded different depressive disorders as a single group. Because this study was performed at a general hospital located in Seoul, the capital of South Korea, participants coming all over the country had different associated symptoms and severities difficult to characterize a specific population. Also, participants had different comorbidities including physical and mental disorders (e.g., somatic symptom and related disorders, trauma- and stressor- related disorders, sleep-wake disorders etc.) Therefore, further study classifying depressive disorders with the severity and symptomatology may be required. Fifth, high risk groups are excluded from the study; exclusion criteria such as substance abuse could make a biased population due to the high comorbidity between substance use disorders and depressive/anxiety disorders. Sixth, our study could have been improved by using previous medical records. Because participants were joined and evaluated at their first visit, previous medical records of them could not be identified. We did not consider past substance abuse which could have contributed to suicidality. Finally, although suicide attempts are a definite behavioral indicator of suicide, they cannot evaluate the severity and frequency of suicidal ideation and any specific plans for suicide attempts. According to the continuum model of suicide, suicidal ideation has been shown to be an important indicator of future suicide attempts (109). Therefore, further study assessing various aspects of suicidality with several scales and detailed clinical interviews may be required.

Identifying independent factors associated with suicide attempts might be important for establishing effective plans of suicide prevention. Clinicians need to be aware of the types of childhood maltreatment and the broad range of household dysfunction they may encounter. An awareness of the relationship between specific types of childhood abuse and suicide attempts may benefit interventions for people with depression. In particular, early prevention efforts aimed at children who have experienced sexual and emotional abuse may reduce their risks for the development of suicide. In addition, an assessment of spirituality level in conjunction with psychiatric risk factors may also be recommended in screening patients at risk of suicide. A brief spiritual history is recommended for all patients visiting psychiatric clinics. The findings of

\section{REFERENCES}

1. Barraclough B, Bunch J, Nelson B, Sainsbury P. A hundred cases of suicide: clinical aspects. $B r \quad J$ Psychiatry. (1974) 125:355-73. doi: 10.1192/bjp.125.4.355

2. Goldstein RB, Black DW, Nasrallah A, Winokur G. The prediction of suicide. Sensitivity, specificity, and predictive value of a multivariate model applied to suicide among 1906 patients with affective disorders. Arch Gen Psychiatry. (1991) 48:418-22. doi: 10.1001/archpsyc.1991.01810290030004

3. Harris EC, Barraclough B. Suicide as an outcome for mental disorders. A meta-analysis. Br J Psychiatry. (1997) 170:205-28. doi: 10.1192/bjp.170.3.205

4. Hawton K, van Heeringen K. Suicide. Lancet. (2009) 373:137281. doi: 10.1016/S0140-6736(09)60372-X this study highlight the associations between spiritual wellbeing and suicide in patients with depression, which should prompt clinicians to take into account spirituality in an effort to improve psychological well-being in patients with depression and/or anxiety. In conclusion, an assessment and strategic interventions to decrease depression and support spirituality might be significant for suicide prevention.

\section{DATA AVAILABILITY STATEMENT}

The raw data supporting the conclusions of this article will be made available by the authors, without undue reservation.

\section{ETHICS STATEMENT}

The studies involving human participants were reviewed and approved by The Institutional Review Board of the Ethics Committee of Seoul St. Mary's Hospital at The Catholic University of Korea (KC09FZZZ0211). The patients/participants provided their written informed consent to participate in this study.

\section{AUTHOR CONTRIBUTIONS}

HT was involved in conceiving of the study, carrying out all aspects of the data collection and analysis, and writing of the manuscript. J-HC provided critical feedback and aided in editing the first draft. All authors contributed to and have approved the final manuscript.

\section{FUNDING}

This study was supported by a grant of the Korea Health Technology R\&D Project through the Korea Health Industry Development Institute (KHIDI), funded by the Ministry of Health \& Welfare, Republic of Korea (Grant Number: HL19C0007). The authors are grateful to the staff at the Department of Psychiatry, Seoul St. Mary's Hospital and Catholic Biomedical Industrial Institute for their assistance with instrumentation, fieldwork, and consultation on data analysis.

5. Roelands M, Vanoverloop J, Maron L, Bilsen J. Socioeconomic risk factors for hospital admittance due to a suicide attempt in Belgium: a population-based study using administrative data. Soc Psychiatry Psychiatr Epidemiol. (2018) 53:53-61. doi: 10.1007/s00127-017-1458-x

6. Werbeloff N, Dohrenwend BP, Levav I, Haklai Z, Yoffe R, Large M, et al. Demographic, behavioral, and psychiatric risk factors for suicide. Crisis. (2016) 37:104-11. doi: 10.1027/0227-5910/a000359

7. Crump C, Sundquist K, Sundquist J, Winkleby MA. Sociodemographic, psychiatric and somatic risk factors for suicide: a Swedish national cohort study. Psychol Med. (2014) 44:279-89. doi: 10.1017/S0033291713000810

8. de Araujo RM, Lara DR. More than words: the association of childhood emotional abuse and suicidal behavior. Eur Psychiatry. (2016) 37:1421. doi: 10.1016/j.eurpsy.2016.04.002 
9. Harford TC, Yi HY, Grant BF. Associations between childhood abuse interpersonal aggression suicide attempt among U.S. adults in a national study. Child Abuse Negl. (2014) 38:138998. doi: 10.1016/j.chiabu.2014.02.011

10. Obikane E, Shinozaki T, Takagi D, Kawakami N. Impact of childhood abuse on suicide-related behavior: analysis using marginal structural models. $J$ Affect Disord. (2018) 234:224-30. doi: 10.1016/j.jad.2018.02.034

11. Sachs-Ericsson NJ, Rushing NC, Stanley IH, Sheffler J. In my end is my beginning: developmental trajectories of adverse childhood experiences to late-life suicide. Aging Ment Health. (2016) 20:139-65. doi: 10.1080/13607863.2015.1063107

12. Kimonis ER, Skeem JL, Edens JF, Douglas KS, Lilienfeld SO, Poythress NG. Suicidal and criminal behavior among female offenders: the role of abuse and psychopathology. J Pers Disord. (2010) 24:581-609. doi: 10.1521/pedi.2010.24.5.581

13. Verona E, Sachs-Ericsson N, Joiner TE Jr. Suicide attempts associated with externalizing psychopathology in an epidemiological sample. Am J Psychiatry. (2004) 161:444-51. doi: 10.1176/appi.ajp.161.3.444

14. Brown GK, Beck AT, Steer RA, Grisham JR. Risk factors for suicide in psychiatric outpatients: a 20-year prospective study. J Consult Clin Psychol. (2000) 68:371-7. doi: 10.1037/0022-006X.68.3.371

15. Maris RW. Suicide. Lancet. (2002) 360:31926. doi: 10.1016/S0140-6736(02)09556-9

16. Silverman MM. Challenges to classifying suicidal ideations, communications, and behaviours. In: International Handbook of Suicide Prevention: Research, Policy and Practice. Hoboken, NJ: Wiley Blackwell. (2011). p. 7-25.

17. Dhingra K, Boduszek D, O'Connor RC. A structural test of the Integrated Motivational-Volitional model of suicidal behaviour. Psychiatry Res. (2016) 239:169-78. doi: 10.1016/j.psychres.2016.03.023

18. Pratt HD, Greydanus DE. Adolescent violence: concepts for a new millennium. Adolesc Med. (2000) 11:103-25.

19. Loureiro ACT, de Rezende Coelho MC, Coutinho FB, Borges LH, Lucchetti $\mathrm{G}$. The influence of spirituality and religiousness on suicide risk and mental health of patients undergoing hemodialysis. Compr Psychiatry. (2018) 80:3945. doi: 10.1016/j.comppsych.2017.08.004

20. Sansone RA, Wiederman MW. Religiosity/spirituality: relationships with non-suicidal self-harm behaviors and attempted suicide. Int J Soc Psychiatry. (2015) 61:762-7. doi: 10.1177/0020764015579738

21. Koenig HG, George LK, Titus P. Religion, spirituality, and health in medically ill hospitalized older patients. J Am Geriatr Soc. (2004) 52:55462. doi: 10.1111/j.1532-5415.2004.52161.x

22. Esposito CL, Clum GA. Social support and problem-solving as moderators of the relationship between childhood abuse and suicidality: applications to a delinquent population. J Trauma Stress. (2002) 15:137-46. doi: 10.1023/A:1014860024980

23. Joiner TEJr, Van Orden KA, Witte TK, Selby EA, Ribeiro JD, Lewis R, et al. Main predictions of the interpersonal-psychological theory of suicidal behavior: empirical tests in two samples of young adults. J Abnorm Psychol. (2009) 118:634-46. doi: 10.1037/a0016500

24. TE Jr, J. Why People Die by Suicide. Cambridge, MA: Harvard University Press (2005).

25. Mann JJ, Apter A, Bertolote J, Beautrais A, Currier D, Haas A, et al. Suicide prevention strategies: a systematic review. JAMA. (2005) 294:206474. doi: 10.1001/jama.294.16.2064

26. Klonsky ED, May AM, Saffer BY. Suicide, suicide attempts, and suicidal ideation. Annu Rev Clin Psychol. (2016) 12:30730. doi: 10.1146/annurev-clinpsy-021815-093204

27. Sheehan DV, Lecrubier Y, Sheehan KH, Amorim P, Janavs J, Weiller E, et al. The Mini-International Neuropsychiatric Interview (M.I.N.I.): the development and validation of a structured diagnostic psychiatric interview for DSM-IV and ICD-10. J Clin Psychiatry. (1998) 59 (Suppl. 20):2233; quiz 34-57.

28. Suominen K, Isometsä E, Suokas J, Haukka J, Achte K, Lönnqvist J. Completed suicide after a suicide attempt: a 37-year follow-up study. Am J Psychiatry. (2004) 161:562-3. doi: 10.1176/appi.ajp.161.3.562

29. Baca-Garcia E, Perez-Rodriguez MM, Keyes KM, Oquendo MA, Hasin DS, Grant BF, et al. Suicidal ideation suicide attempts among Hispanic subgroups in the United States: 1991-1992 2001-2002. J Psychiatr Res. (2011) 45:512-8. doi: 10.1016/j.jpsychires.2010.09.004

30. Wiglusz MS, Landowski J, Michalak L, Cubala WJ. Validation of the Polish version of the Beck Depression Inventory in patients with epilepsy. Epilepsy Behav. (2017) 77:58-61. doi: 10.1016/j.yebeh.2017.09.023

31. Hwang SH, Rhee MK, Kang RH, Lee HY, Ham BJ, Lee YS, et al. Development and validation of a screening scale for depression in Korea: the Lee and Rhee Depression Scale. Psychiatry Investig. (2012) 9:3644. doi: 10.4306/pi.2012.9.1.36

32. Shim EJ, Jeon HJ, Kim H, Lee KM, Jung D, Noh HL, et al. Measuring stress in medical education: validation of the Korean version of the higher education stress inventory with medical students. BMC Med Educ. (2016) 16:302. doi: 10.1186/s12909-016-0824-9

33. Suh S, Ryu H, Chu C, Hom M, Rogers ML, Joiner T. Validation of the korean depressive symptom inventory-suicidality subscale. Psychiatry Investig. (2017) 14:577-84. doi: 10.4306/pi.2017.14.5.577

34. Julian LJ. Measures of anxiety: state-trait anxiety inventory (STAI), beck anxiety Inventory (BAI), and hospital anxiety and depression scale-Anxiety (HADS-A). Arthritis Care Res. (2011) 63 Suppl 11:S46772. doi: 10.1002/acr.20561

35. Hahn D-W. Korean adaptation of Spielberger's STAI (K-STAI). Kor J Health Psychol. (1996) 1:1-14.

36. Barbosa LP, Quevedo L, da Silva Gdel G, Jansen K, Pinheiro RT, Branco J, et al. Childhood trauma and suicide risk in a sample of young individuals aged 14-35 years in southern Brazil. Child Abuse Negl. (2014) 38:11916. doi: 10.1016/j.chiabu.2014.02.008

37. Roy A. Combination of family history of suicidal behavior and childhood trauma may represent correlate of increased suicide risk. J. Affect. Disord. (2011) 130:205-8. doi: 10.1016/j.jad.2010.09.022

38. Roy A, Carli V, Sarchiapone M. Resilience mitigates the suicide risk associated with childhood trauma. J Affect Disord. (2011) 133:5914. doi: 10.1016/j.jad.2011.05.006

39. Heim C, Nater UM, Maloney E, Boneva R, Jones JF, Reeves WC. Childhood trauma and risk for chronic fatigue syndrome: association with neuroendocrine dysfunction. Arch Gen Psychiatry. (2009) 66:7280. doi: 10.1001/archgenpsychiatry.2008.508

40. Kim D, Park SC, Yang H, Oh DH. Reliability and validity of the korean version of the childhood trauma questionnaireshort form for psychiatric outpatients. Psychiatry Investig. (2011) 8:305-11. doi: 10.4306/pi.2011.8.4.305

41. Peterman AH, Fitchett G, Brady MJ, Hernandez L, Cella D. Measuring spiritual well-being in people with cancer: the functional assessment of chronic illness therapy-Spiritual Well-being Scale (FACIT-Sp). Ann Behav Med. (2002) 24:49-58. doi: 10.1207/S15324796ABM2401_06

42. Canada AL, Murphy PE, Fitchett G, Peterman AH, Schover LR. A 3-factor model for the FACIT-Sp. Psychooncology. (2008) 17:90816. doi: 10.1002/pon.1307

43. Murphy PE, Canada AL, Fitchett G, Stein K, Portier K, Crammer C, et al. An examination of the 3 -factor model and structural invariance across racial/ethnic groups for the FACIT-Sp: a report from the American Cancer Society's Study of Cancer Survivors-II (SCS-II). Psychooncology. (2010) 19:264-72. doi: 10.1002/pon.1559

44. Lee YJ, Kim CM, Linton JA, et al. Association between spiritual wellbeing and pain, anxiety and depression in terminal cancer patients: a pilot study. Kor J Hospice Palliative Care. (2013) 16:175-82. doi: 10.14475/kjhpc.2013.16.3.175

45. Suh SY, Im YS, Lee SH, Park MS, Yoo T. A study for the development of Korean version of the Duke-UNC functional social support questionnaire. $J$ Kore Acad Family Med. (1997) 18:250-60.

46. Cohen J. Statistical approaches to suicidal risk factor analysis. Ann N Y Acad Sci. (1986) 487:34-41. doi: 10.1111/j.1749-6632.1986.tb27883.x

47. Dunn ME, Burbine T, Bowers CA, Tantleff-Dunn S. Moderators of stress in parents of children with autism. Commu Ment Health J. (2001) 37:3952. doi: 10.1023/A:1026592305436

48. Weiss MJ. Harrdiness and social support as predictors of stress in mothers of typical children, children with autism, and children with mental retardation. Autism. (2002) 6:115-30. doi: 10.1177/1362361302006001009

49. White-Koning M, Grandjean H, Colver A, Arnaud C. Parent and professional reports of the quality of life of children with cerebral palsy and 
associated intellectual impairment. Dev Med Child Neurol. (2008) 50:61824. doi: 10.1111/j.1469-8749.2008.03026.x

50. Allen D, Marshall ES. Spirituality as a coping resource for African American parents of chronically ill children. MCN Am J Matern Child Nurs. (2010) 35:232-7. doi: 10.1097/NMC.0b013e3181de3f76

51. Hastings RP, Kovshoff H, Brown T, Ward NJ, Espinosa FD, Remington B. Coping strategies in mothers and fathers of preschool and school-age children with autism. Autism. (2005) 9:377-91. doi: 10.1177/1362361305056078

52. Baron RM, Kenny DA. The moderator-mediator variable distinction in social psychological research: conceptual, strategic, and statistical considerations. $J$ Pers Soc Psychol. (1986) 51:1173-82. doi: 10.1037/0022-3514.51.6.1173

53. Draper B, Pfaff JJ, Pirkis J, Snowdon J, Lautenschlager NT, Wilson I, et al. Long-term effects of childhood abuse on the quality of life and health of older people: results from the depression and early prevention of suicide in general practice project. J Am Geriatr Soc. (2008) 56:26271. doi: 10.1111/j.1532-5415.2007.01537.x

54. Dube SR, Anda RF, Felitti VJ, Chapman DP, Williamson DF, Giles WH. Childhood abuse, household dysfunction, and the risk of attempted suicide throughout the life span: findings from the adverse childhood experiences study. JAMA. (2001) 286:3089-96. doi: 10.1001/jama.286.24.3089

55. Fuller-Thomson E, Baird SL, Dhrodia R, Brennenstuhl S. The association between adverse childhood experiences (ACEs) and suicide attempts in a population-based study. Child Care Health Dev. (2016) 42:72534. doi: $10.1111 /$ cch. 12351

56. Mueller PS, Plevak DJ, Rummans TA. Religious involvement, spirituality, and medicine: implications for clinical practice. Mayo Clin Proc. (2001) 76:1225-35. doi: $10.4065 / 76.12 .1225$

57. Daniel TR, Shay-Lee B, Brenda E, Laurence YK, Murray E, Jitender S, et al. Spirituality, religion and suicidal behavior in a nationally representative sample. J Affect Disord. (2009) 114:32-40. doi: 10.1016/j.jad.2008.08.007

58. Sobel ME. Asymptotic confidence intervals for indirect effects in structural equation models. Sociol Methodol. (1982) 13:290-312. doi: 10.2307/270723

59. Beck AT, Ward CH, Mendelson M, Mock J, Erbaugh J. An inventory for measuring depression. Arch Gen Psychiatry. (1961) 4:561-71. doi: 10.1001/archpsyc.1961.01710120031004

60. Marteau TM, Bekker H. The development of a six-item short-form of the state scale of the Spielberger State-Trait Anxiety Inventory (STAI). Br J Clin Psychol. (1992) 31 (Pt 3):301-6. doi: 10.1111/j.2044-8260.1992.tb00997.x

61. van der Bij AK, de Weerd S, Cikot RJ, Steegers EA, Braspenning JC. Validation of the dutch short form of the state scale of the Spielberger StateTrait Anxiety Inventory: considerations for usage in screening outcomes. Community Genet. (2003) 6:84-7. doi: 10.1159/000073003

62. Deborah D, Gwenole L, Deborah D, Carla G, Patrizia Z, Sebastien G, et al. Depress Anxiety. (2018) 35:382-92. doi: 10.1002/da.22709

63. Winer ES, Drapeau CW, Veilleux JC, Nadorff MR. The association between anhedonia, suicidal ideation, and suicide attempts in a large student sample. Arch Suicide Res. (2016) 20:265-72. doi: 10.1080/13811118.2015.1025119

64. Xie W, Li H, Luo X, Fu R, Ying X, Wang N, et al. Anhedonia and pain avoidance in the suicidal mind: behavioral evidence for motivational manifestations of suicidal ideation in patients with major depressive disorder. J Clin Psychol. (2014) 70:681-92. doi: 10.1002/jclp.22055

65. Wolfe KL, Nakonezny PA, Owen VJ, Rial KV, Moorehead AP, Kennard BD, et al. Hopelessness as a predictor of suicide ideation in depressed male and female adolescent youth. Suicide Life Threat Behav. (2017) 49:253-63. doi: $10.1111 /$ sltb. 12428

66. Chabrol H, Choquet M. Relationship between depressive symptoms, hopelessness and suicidal ideation among 1547 high school students. Encephale. (2009) 35:443-7. doi: 10.1016/j.encep.2008.10.010

67. Davidson JR, Hughes DC, George LK, Blazer DG. The association of sexual assault and attempted suicide within the community. Arch Gen Psychiatry. (1996) 53:550-5. doi: 10.1001/archpsyc.1996.01830060096013

68. Garnefski N, Arends E. Sexual abuse and adolescent maladjustment: differences between male and female victims. J Adolesc. (1998) 21:99107. doi: 10.1006/jado.1997.0132

69. Maniglio R. The role of child sexual abuse in the etiology of suicide and non-suicidal self-injury. Acta Psychiatr. Scand. (2011) 124:3041. doi: 10.1111/j.1600-0447.2010.01612.x
70. Brown J, Cohen P, Johnson JG, Smailes EM. Childhood abuse and neglect: specificity of effects on adolescent and young adult depression and suicidality. J Am Acad Child Adolesc Psychiatry. (1999) 38:14906. doi: 10.1097/00004583-199912000-00009

71. Ryan G. Preventing violence and trauma in the next generation. $J$ Interpers Violence. (2005) 20:132-41. doi: 10.1177/088626050 4268605

72. McKinney JM, Hirsch JK, Britton PC. PTSD symptoms and suicide risk in veterans: serial indirect effects via depression and anger. J Affect Disord. (2017) 214:100-7. doi: 10.1016/j.jad.2017.03.008

73. Allen B. An analysis of the impact of diverse forms of childhood psychological maltreatment on emotional adjustment in early adulthood. Child Maltreat. (2008) 13:307-12. doi: 10.1177/1077559508318394

74. Egeland B. Taking stock: childhood emotional maltreatment and developmental psychopathology. Child Abuse Negl. (2009) 33:22-6. doi: 10.1016/j.chiabu.2008.12.004

75. Wright MO, Crawford E, Del Castillo D. Childhood emotional maltreatment and later psychological distress among college students: the mediating role of maladaptive schemas. Child Abuse Negl. (2009) 33:59-68. doi: 10.1016/j.chiabu.2008.12.007

76. Cotton S, Kudel I, Roberts YH, Pallerla H, Tsevat J, Succop $\mathrm{P}$, et al. Spiritual well-being and mental health outcomes in adolescents with or without inflammatory bowel disease. $J$ Adolesc Health. (2009) 44:485-92. doi: 10.1016/j.jadohealth.2008. 09.013

77. Baetz M, Griffin R, Bowen R, Koenig HG, Marcoux E. The association between spiritual and religious involvement and depressive symptoms in a Canadian population. J Nerv Ment Dis. (2004) 192:818-22. doi: 10.1097/01.nmd.0000146735.73827.85

78. Morris LE. A spiritual well-being model: use with older women who experience depression. Issues Ment Health Nurs. (1996) 17:43955. doi: 10.3109/01612849609009412

79. Litwinczuk KM, Groh CJ. The relationship between spirituality, purpose in life, and well-being in HIV-positive persons. J Assoc Nurses AIDS Care. (2007) 18:13-22. doi: 10.1016/j.jana.2007.03.004

80. Trevino KM, Pargament KI, Cotton S, Leonard AC, Hahn J, Caprini-Faigin CA, et al. Religious coping and physiological, psychological, social, and spiritual outcomes in patients with HIV/AIDS: cross-sectional and longitudinal findings. AIDS Behav. (2010) 14:379-89. doi: 10.1007/s10461-007-9332-6

81. Folkman S, Moskowitz JT. Positive affect and the other side of coping. Am Psychol. (2000) 55:647-54. doi: 10.1037/0003-066X.55.6.647

82. Abdollahi A, Abu Talib M. Spirituality moderates hopelessness, and suicidal ideation among iranian depressed adolescents. Death Stud. (2015) 39:57983. doi: $10.1080 / 07481187.2015 .1013163$

83. Abdollahi A, Abu Talib M. Hardiness, spirituality, and suicidal ideation among individuals with substance abuse: the moderating role of gender and marital status. J Dual Diagn. (2015) 11:12-21. doi: 10.1080/15504263.2014.988558

84. McClain-Jacobson C, Rosenfeld B, Kosinski A, Pessin H, Cimino JE, Breitbart W. Belief in an afterlife, spiritual well-being and end-of-life despair in patients with advanced cancer. Gen Hosp Psychiatry. (2004) 26:4846. doi: 10.1016/j.genhosppsych.2004.08.002

85. Wu A, Wang J-Y, Jia C-X. Religion and completed suicide: a meta-analysis. PLoS ONE. (2015) 10:e131715. doi: 10.1371/journal.pone.0131715

86. Koenig HG. Spirituality in Patient Care. Radnor, PA: Templeton Foundation Press (2002).

87. Knox S, Catlin L, Casper M, Schlosser LZ. Addressing religion and spirituality in psychotherapy: clients' perspectives 1. Psychother Res. (2005) 15:287-303. doi: 10.1080/10503300500090894

88. Walsh R. The search for synthesis: transpersonal psychology and the meeting of east and west, psychology and religion, personal and transpersonal. $J$ Humanistic Psychol. (1992) 32:19-45. doi: 10.1177/0022167892321003

89. Wallace BA, Shapiro SL. Mental balance and well-being: building bridges between Buddhism and Western psychology. Am Psychol. (2006) 61:690701. doi: 10.1037/0003-066X.61.7.690

90. Yong J, Kim J, Park J, Seo I, Swinton J. Effects of a spirituality training program on the spiritual and psychosocial well-being of hospital 
middle manager nurses in Korea. J Contin Educ Nurs. (2011) 42:2808. doi: 10.3928/00220124-20101201-04

91. Bormann JE, Becker S, Gershwin M, Kelly A, Pada L, Smith TL, et al. Relationship of frequent mantram repetition to emotional and spiritual well-being in healthcare workers. J Contin Educ Nurs. (2006) 37:21824. doi: 10.3928/00220124-20060901-02

92. Richards TA, Oman D, Hedberg J, Thoresen CE, Bowden J. A qualitative examination of a spiritually-based intervention and self-management in the workplace. Nurs Sci Q. (2006) 9:231-9. doi: 10.1177/0894318406289490

93. Pompili M, Innamorati M, Di Vittorio C, Sher L, Girardi P, Amore M. Sociodemographic and clinical differences between suicide ideators and attempters: a study of mood disordered patients 50 years and older. Suicide Life Threat Behav. (2014) 44:34-45. doi: 10.1111/sltb.12051

94. Suppapitiporn S, Thavichachart N, Suppapitiporn S. Social support in depressed patients who attempted suicide. J Med Assoc Thai. (2004) 87(Suppl 2):S266-71.

95. Aaronson LS. Perceived and received support: effects on health behavior during pregnancy. Nurs Res. (1989) 38:49. doi: 10.1097/00006199-198901000-00002

96. Feldman PJ, Dunkel-Schetter C, Sandman CA, Wadhwa PD. Maternal social support predicts birth weight and fetal growth in human pregnancy. Psychosom Med. (2000) 62:715-25. doi: 10.1097/00006842-20000900000016

97. Broadhead WE, Gehlbach SH, de Gruy FV, Kaplan BH. The Duke-UNC functional social support questionnaire. Measurement of social support in family medicine patients. Med Care. (1988) 26:709-23. doi: 10.1097/00005650-198807000-00006

98. Broadhead WE, Gehlbach SH, deGruy FV, Kaplan BH. Functional versus structural social support and health care utilization in a family medicine outpatient practice. Med Care. (1989) 27:221-33. doi: 10.1097/00005650-198903000-00001

99. Pietrzak RH, Russo AR, Ling Q, Southwick SM. Suicidal ideation in treatment-seeking Veterans of Operations Enduring Freedom and Iraqi Freedom: the role of coping strategies, resilience, and social support. J Psychiatr Res. (2011) 45:720-6. doi: 10.1016/j.jpsychires.2010. 11.015

100. Shilubane HN, Ruiter RA, Bos AE, van den Borne B, James S, Reddy PS. Psychosocial correlates of suicidal ideation in rural South African adolescents. Child Psychiatry Hum Dev. (2014) 45:153-62. doi: 10.1007/s10578-013-0387-5

101. Lyu D, Wu Z, Wang Y, Huang Q, Wu Z, Cao T, et al. Disagreement and factors between symptom on self-report and clinician rating of major depressive disorder: a report of a national survey in
China. J Affect Disord. (2019) 253:141-6. doi: 10.1016/j.jad.2019. 04.073

102. Uher R, Perlis RH, Placentino A, Dernovšek MZ, Henigsberg N, Mors O, et al. Self-report and clinician-rated measures of depression severity: can one replace the other? Depress Anxiety. (2012) 29:1043-9. doi: 10.1002/da. 21993

103. Breslau N, Davis GC. DSM-III generalized anxiety disorder: an empirical investigation of more stringent criteria. Psychiatry Res. (1985) 15:2318. doi: 10.1016/0165-1781(85)90080-0

104. Kendler KS, Gardner CO, Gatz M, Pedersen NL. The sources of comorbidity between major depression and generalized anxiety disorder in a Swedish national twin sample. Psychol Med. (2007) 37:45362. doi: 10.1017/S0033291706009135

105. Kendler KS, Neale MC, Kessler RC, Heath AC, Eaves LJ. Major depression and generalized anxiety disorder. Same genes, (partly) different environments? Arch Gen Psychiatry. (1992) 49:716-22. doi: 10.1001/archpsyc.1992.01820090044008

106. Kendler KS, Hettema JM, Butera F, Gardner CO, Prescott CA. Life event dimensions of loss, humiliation, entrapment, and danger in the prediction of onsets of major depression and generalized anxiety. Arch Gen Psychiatry. (2003) 60:789-96. doi: 10.1001/archpsyc.60.8.789

107. Kessler RC. The effects of stressful life events on depression. Annu Rev Psychol. (1997) 48:191-214. doi: 10.1146/annurev.psych.48.1.191

108. Price M, Higa-McMillan C, Ebesutani C, Okamura K, Nakamura BJ, Chorpita BF, et al. Symptom differentiation of anxiety and depression across youth development and clinic-referred/nonreferred samples: An examination of competing factor structures of the Child Behavior Checklist DSM-oriented scales. Dev Psychopathol. (2013) 25:1005-15. doi: 10.1017/S0954579413000333

109. Kessler RC, Borges G, Walters EE. Prevalence of and risk factors for lifetime suicide attempts in the National Comorbidity Survey. Arch Gen Psychiatry. (1999) 56:617-26. doi: 10.1001/archpsyc.56.7.617

Conflict of Interest: The authors declare that the research was conducted in the absence of any commercial or financial relationships that could be construed as a potential conflict of interest.

Copyright (C) 2021 Tae and Chae. This is an open-access article distributed under the terms of the Creative Commons Attribution License (CC BY). The use, distribution or reproduction in other forums is permitted, provided the original author(s) and the copyright owner(s) are credited and that the original publication in this journal is cited, in accordance with accepted academic practice. No use, distribution or reproduction is permitted which does not comply with these terms. 